\title{
Erythropoietin Treatment in Chronic Renal Failure Anaemia-Biosimilar Option in the Rational Use of Medicine Process in Order to Reduced Public Health Economic Burden
}

\author{
Gustavo H. Marin ${ }^{1,2 *}$, Lupe Marin ${ }^{1,3}$, Griselda Haag ${ }^{1}$, Paula Risso ${ }^{1}$ and Jorge Errecalde ${ }^{1}$ \\ ${ }^{1}$ Pharmacology Department, Faculty of Medicine, National University of La Plata, Argentina \\ ${ }^{2}$ CONICET - National Council of Scientific and Technical Research, Argentina \\ ${ }^{3}$ Commissions of Scientific Research, Buenos Aires, Rinchi Borahi, Argentina
}

\begin{abstract}
Biopharmaceuticals innovation molecules have changed the course of a large number of chronic diseases Many of these molecules became Gold Standards in oncology, rheumatology and other illness. However, their cost makes these drugs unattainable for most patients, and often put the health systems' budgets at risk. This study takes the anaemia due to Chronic Renal Failure disease (CRFD) as an example to a rational selection of treatment with erythropoietin (EPO) and compares the trade brand mark of this drug with biosimilars option. Prescriptions of EPO in 394 patients with CRFD were submitted to a protocol of rational selection based in efficacy/risk ratio demonstration. This protocol was able to reduce that initial number to 91 cases that could really benefited with EPO treatment. These patients were included in a cohort study that compared EPO trade mark with biosimilars option. The experience demonstrated equal clinical outcomes in both groups but a reduction to half the original cost when biosimilars were dispensed. Biosimilars demonstrated to be a cheap and safe option to increase medicine access for anaemia associated to CRFD.
\end{abstract}

Keywords: Biosimilars; Anaemia; Chronic; Failure; Renal; Cost

\section{Introduction}

Biopharmaceuticals products are drugs containing substances derived from biotechnology as active ingredients [1]. These molecules were developed back in the early 1980s and certainly changed the course of a large number of chronic diseases and have inadvertently been introduced into the daily lives of patients suffering from hepatitis, rheumatoid arthritis, chronic kidney failure, diabetes, multiple sclerosis, cancer and other pathologies that were previously untreated.

Traditional medicines are made by chemical synthesis processes and have simple chemical structures. In contrast, biotechnology drugs are manufactured using microorganisms such as bacteria or mammalian cells. The success of this technology was such that in the last decade have introduced to the market more than 200 therapeutic molecules existing on a global scale.

Many of these molecules became Gold Standards in oncology, rheumatology and other high-impact diseases, however, their cost are up to 200,000 USD/Y (almost 100 times cost of a traditional drug) [2]. This high cost is usually due to the complexity of its structure, as well as the manufacturing, the control and the research processes [3]. Those Pharmaceutical companies that develop a new product claim by itself the patent of the discovery [4,5], and anyone that wants to produce these molecules, has to pay a high fee.

Hence, this situation avoids market competition and sustain over time soaring prices that health systems may not assimilate in the future. For this reason, the access to these medicines will not be guarantee for everyone. Governments must arbitrate the measures to provide suitable coverage to the population with these needs. One of the best strategies to do so is the adoption of a policy on the rational use of medicines. This means select medicines with proven efficacy and with the best benefit/risk/cost ratio. After the selection of the most effective and safest active ingredients, other actions can be carried out in the direction of choosing the best alternative in the market. Due to the fact that some patents of the original biological molecules have recently expired, or local pharmaceutical companies to develop and produce either generic or biosimilars drugs.

Biosimilars differ from conventional generic drugs in various aspects, such as the size of the active substance, its complexity, the nature of the manufacturing process and the fact that they are not identical to the original products [6]. Biosimilars might be then pharmaceutical alternatives of "innovative" products at a lower cost [7-10]. In order to demonstrate so, we performed a strategy of RUM followed by a cohort study in which biosimilars were compared with original molecules in terms of clinical outcomes and cost of treatments to treat anaemia associated to Chronic Renal Failure disease.

\section{Methods}

\section{Type of study}

This is a cohort single center trial submitted to CICPA institutional review board. It was framed in two stages: the first one based in a rational selection of medicines strategy in order to validate the Erythropoietin (EPO) indication to treat the anaemia associate to Chronic Renal Failure disease (CRFD) in patients under haemodialysis.

The second stage was the development of a cohort study in which patients were divided in two groups based on the type Erythropoietin (EPO) used to treat the disease either original trade mark or biosimilars molecule.

*Corresponding author: Gustavo H. Marin, Pharmacology Department, Faculty of Medicine, National University of La Plata, Buenos Aires, Argentina, Tel: +5492215030058; E-mail: gmarin2009@gmail.com

Received July 10, 2018; Accepted July 30, 2018; Published August 06, 2018

Citation: Marin GH, Marin L, Haag G, Risso P, Errecalde J (2018) Erythropoietin Treatment in Chronic Renal Failure Anaemia-Biosimilar Option in the Rationa Use of Medicine Process in Order to Reduced Public Health Economic Burden. J Bioanal Biomed 10:96-99. doi:10.4172/1948-593X.1000214

Copyright: $\odot 2018$ Marin $\mathrm{GH}$, et al. This is an open-access article distributed under the terms of the Creative Commons Attribution License, which permits unrestricted use, distribution, and reproduction in any medium, provided the original author and source are credited. 
Citation: Marin GH, Marin L, Haag G, Risso P, Errecalde J (2018) Erythropoietin Treatment in Chronic Renal Failure Anaemia-Biosimilar Option in the Rational Use of Medicine Process in Order to Reduced Public Health Economic Burden. J Bioanal Biomed 10:96-99. doi:10.4172/1948593X.1000214

Sample size determined according the following formula:

$$
\begin{gathered}
\mathrm{n}:\left\{\mathrm{Z}_{\alpha} \sqrt{ } 2 \mathrm{xpx}(1-\mathrm{p})+\mathrm{Z}_{\beta} \sqrt{ } \mathrm{p}_{1} \mathrm{x}\left(1-\mathrm{p}_{1}\right)+\mathrm{p}_{2} \mathrm{x}\left(1-\mathrm{p}_{2}\right)\right\} \\
\left(\mathrm{p}_{1}-\mathrm{p}_{2}\right)^{2}
\end{gathered}
$$

Where: $Z_{\alpha}$ : is the value that corresponds to the $95 \%$ confidence level ( $\alpha$ error).

$Z_{\beta}$ : is the value that corresponds to the power of the study to detect differences between the values of the baseline and post intervention ( $80 \%$ power of the test, $20 \%$ error $\beta$ ).

\section{$\mathrm{p}: \mathrm{p}_{1}+\mathrm{p}_{2} / 2$}

$\mathrm{P} 1$ is the proportion of the variables to be evaluated in the population in its baseline.

P2 is the expected proportion of the variables evaluated according to the success of the treatment.

\section{Rational use of medicine (RUM)}

The Rational use of medicine is understood to use the effective medication for the determined health situation, safe, at the adequate dose for the patient, administered by the most convenient way and at the lowest possible cost [11]. Therefore, these aspects (efficacy, safety, convenience and cost) were analysed in each case to ensure the compliance of the RUM.

\section{Population}

Social security beneficiaries of Buenos Aires State coverage, affected by anaemia associated with chronic renal failure in haemodialysis in whom EPO was indicated were included in the study.

\section{Inclusion criteria}

Patients who received dialysis and had anemia caused by terminal renal failure over $18 \mathrm{y}$ with values and hemoglobin $<\mathrm{a} 9.5 \mathrm{gr} / \mathrm{dl}$ and normal ferremia and ferritin and who presented symptomatology at the time of the pre-incorporation study evaluation were eligible for inclusion.

\section{Exclusion criteria}

We excluded from the study the patients with anemia due to functional or absolute iron deficiency; or with malignant comorbidities associated with the underlying disease.

\section{Variables}

Clinical outcome and cost of treatment were the main variables included in the analysis.

\section{Period of study}

$01 / 01 / 2015$ to $31 / 12 / 2016$.

\section{Cost evaluation}

The cost of the medicines was considered as defined daily dose (DDD) for patient treated.
The baseline costs were extrapolated to a national coverage in order to determinate the global cost for Argentina. To compare the cost of each type of EPO ampoules, it was considered the commercial presentation of 2000 Units.

\section{Statistical analysis}

Results obtained from original brand $v s$. biosimilar drug administration were compared by two Chi Square formulas (Pearson Chi Square and Chi Square MV-G2) and Anova tests using InfoStat 7 software. Difference was considered significant when the $\mathrm{p}$ value was $<0.05$.

\section{Results}

The number of patients with CRFD in haemodialysis living in Buenos Aires State during the period of study was 10882 patients (4640 females/6242 males). 1451 of those patients had social security coverage. Prescription of EPO was performed in 394 of those patients. However, after submitting the prescriptions to a RUM analysis the amount that really needed EPO were 91 patients. Patients excluded had either iron or folic acid deficiency or lack the strict criteria of use of EPO. From the 91 patients, only 60 of them had access to the EPO treatment and were included in the present study ( 35 men and 25 women). Their average age was $57+/-14$ y old. Two groups were considered according to the type of EPO dispensed (either original molecule or biosimilars-Figure 1). Basal blood test was performed in all cases (Table 1).

Ferritin values observed ranged from 173 to $987 \mathrm{ng} / \mathrm{ml}$; transferrin saturation (TSAT) oscillated between 19 and 78\%. Serum iron also showed marked oscillations (76.8\%-182\%). Although serum iron profile disparty was observed in these two groups, the results were similar in both of them and not find significant differences were detected (Table 1).

The defined daily dose for Erythropoietin was 1000 Units (or its equipotent dose for biosimilars molecules), assuring a weekly dose of 6000 UI to complete the period of treatment established before the new blood control test. After 4 weeks of treatment, five patients were excluded from protocol ( 2 from trade Mark drug and 3 from biosimilars). The cause of these exclusions was protocol violation in all cases (patients did not respect the weekly dose established in the protocol).

Results of blood test after a month of EPO treatment is shown in Table 2. It is also shown in that table, the improvement of performance status referred by the patients in relation to basal survey. With regard to the cost of EPO, the first surprising observation is that for the presentation of ampoules of $2000 \mathrm{U}$, there is a difference of $340 \%$ compared to the costs of the original biological molecule, but the most remarkable affair was that even between biosimilars, the cost of the most expensive option doubles the cheaper one. (21.77 USD vs. 9.6 USD per ampoule of $2000 \mathrm{U}$ ) (Table 3).

\section{Discussion}

Biosimilars pricing worldwide has commonly obtain cost reductions up to $30 \%$ less than the reference products $[12,13]$, however our shows that there are still opportunities for biosimilars to provide even more significant discounts in certain countries.
Group A (Trade Mark molecule)

Group B (Biosimilars drugs)
Clinical Impact (in terms of $\mathrm{Hb}$ recovery)

Figure 1: Cohort of Patients according to group of treatment. 
Citation: Marin GH, Marin L, Haag G, Risso P, Errecalde J (2018) Erythropoietin Treatment in Chronic Renal Failure Anaemia-Biosimilar Option in the Rational Use of Medicine Process in Order to Reduced Public Health Economic Burden. J Bioanal Biomed 10:96-99. doi:10.4172/1948593X.1000214

\begin{tabular}{|c|c|c|c|c|c|c|c|}
\hline Group according to type of EPO & n & $\begin{array}{l}\mathrm{Hb} \\
\mathrm{gr} / \mathrm{dl}\end{array}$ & $\begin{array}{l}\mathrm{Ht} \\
\%\end{array}$ & $\begin{array}{l}\text { Ferritin } \\
\mathrm{ng} / \mathrm{ml}\end{array}$ & $\begin{array}{l}\text { Ferremia } \\
\gamma \%\end{array}$ & TSAT & TIBC \\
\hline Trade mark & 30 & $9.3 \pm 0.9$ & $28 \pm 4$ & $598 \pm 303$ & $88,4 \pm 1$ & $37 \pm 13$ & $159 \pm 22$ \\
\hline Biosimilars & 30 & $9.1 \pm 1.1$ & $27 \pm 1$ & $584 \pm 202$ & $90,5 \pm 7$ & $36 \pm 19$ & $156 \pm 46$ \\
\hline \multicolumn{2}{|l|}{ Statistical difference } & NS & NS & NS & NS & NS & NS \\
\hline
\end{tabular}

Table 1: Baseline data.

EPO: Erithropoietin; Hb: Hemoglobin; Ht: Hematocrit; TSAT: Transferrin; TIBC: Total Iron Transport Capacity.

\begin{tabular}{|l|l|l|l|l|l|l|l|l|}
\hline $\begin{array}{l}\text { Group according to type } \\
\text { of EPO }\end{array}$ & $\mathbf{n}$ & $\mathbf{H b}$ & $\mathbf{H t}$ & Ferritin & Ferremia & TSAT & TIBC \\
\hline Trade mark & 28 & $11.7 \pm 0.6$ & $35 \pm 3$ & $601 \pm 275$ & $78,4 \pm 1$ & $38 \pm 12$ & $159 \pm 22$ & $33,6 \%$ \\
\hline Biosimilars & 27 & $11.8 \pm 1.6$ & $34 \pm 9$ & $597 \pm 263$ & $70,5 \pm 7$ & $38 \pm 16$ & $156 \pm 46$ & $35,1 \%$ \\
\hline Statistical difference & & NS & NS & NS & NS & NS & NS \\
\hline
\end{tabular}

Table 2: Treatment Clinical and Laboratory Outcome.

EPO: Erithropoietin; Upw: Units per Week; Hb: Hemoglobin; Ht: Hematocrit; TSAT: Transferrin; TIBC: Total Iron Transport Capacity.

\begin{tabular}{|l|l|}
\hline Type of EPO & Price USD \\
\hline Original Brand & 22.28 \\
\hline Biosimilar 1 & 12.26 \\
\hline Biosimilar 2 & 21.77 \\
\hline Biosimilar 3 & 9.6 \\
\hline
\end{tabular}

Table 3: Cost analysis of EPO molecules.

Presentation dose were syringe of 2000 UI for all cases. USD: United States Dollar.

Most of the available literature on biosimilars has focused on the critical analysis of their specific market authorization procedure. Only few papers are addressed to demonstrate biosimilars proficiency and its subsequent impact on price erosion [11-13].

Companies that produce brand-name drugs are gradually abandoning their strategy of competing with their biosimilars counterparts for a policy aimed at improving their formulations, expression systems and the delivery methods [14]. For example, Amgen's first-generation epoetin alfa which has multiple weekly doses are changing its strategy towards the development of new products (second-generation epoetin alfa) that provides an only weekly injection. This fact opens a scenario that unfold new opportunities to incorporate classical biosimilars products in emerging markets at a lower price to treat well known disease like anaemia in Chronic Renal Failure Disease (CRFD) in which outcome benefits was already been demonstrated.

CRFD is a global public health problem. The most serious manifestation of renal disease is chronic renal failure that requires dialysis $[15,16]$. Global data shows that the prevalence of Chronic Kidney Disease (CKD) in the elderly is $17 \%$ [17]. The CRFD usually coexists with anaemia that needs high cost medicines like Erythropoietin (EPO) to be treated [18].

In our work is shown that the rational selection of patients that should receive EPO is the most rational cost/effectiveness decision to be made. In fact, after the selection process from the 394 prescriptions done, only in 91 patients the EPO was kept. That means that $76.9 \%$ of the prescriptions were inconsistent with the indication criteria. On the other hand, once the validation of the treatment is demonstrated, the procedure of RUM continues with the selection of the type of EPO it should be used according to cost/effectiveness analysis. Here is where biosimilars have their place.

The present study shows that when biosimilars were used instead of brand market molecules, it could be obtained the same clinical outcomes and also save money of health service budgets in concept of treatment. In economic terms, it could be said that using the selection procedure, there is a net saving of 844.800 USD only considering this drug and for this indication in the State of Buenos Aires, Argentina.

\section{Conclusion}

This study reflects that rational use of medicine procedure may help to select the best treatment for anaemia in CRFD. The RUM procedure performed in this study included the use of a biosimilars selection, which was able to reduce the treatment cost by half of the original price. Policies that promote biosimilars use and production in developing countries like Argentina might result in saving public budget of the health system, which can be a way to include more population into the health care coverage, increasing their access to health services. Proper screening of patients for eligibility/necessity to receive a therapy also helps in reducing healthcare cost, as proved in this study.

Policy makers have then a challenge for in the coming years that will be to set effective measures leading to improved biosimilar uptake. Expectations on future savings for emerging markets like Argentina related to forthcoming biosimilars are a key driver for interest and concern from national authorities on biosimilar current market penetration, which becomes a clear opportunity in terms of savings costs in Health public Institutions.

\section{References}

1. Bingham A, Ekins S (2009) Competitive collaboration in the pharmaceutical and biotechnology industry. Drug Discov Today 23-24: 1079-1081.

2. Goldstein DA, Stemmer SM, Gordon N (2016) The cost and value of cancer drugs-are new innovations outpacing our ability to pay? Isr J Health Policy Res 5: 40 .

3. Marin GH, Polach MA (2011) High-cost drugs: analysis and proposals for Mercosur countries. Rev Panam Salud Publica 2: 167-176.

4. Correa CM (2000) Intellectually Property Rights, the WTO and Developing Countries. The TRIPs Agreement and Policy Options. Zed Books, London, United Kingdom.

5. Correa CM (2006) Implications of bilateral free trade agreements on access to medicines. Bull World Health Organ 84: 399-404.

6. Rovira J, Espín J, García L, Olry de Labry A (2011) The impact of biosimilars entry in the EU market. Granada: Andalusian School of Public Health.

7. Lavarello P (2014) Convergence of biotechnological paradigms and strategies of the world's leading groups. Problemas del desarrollo 45: 9-35.

8. Pisano GP (2006) Science business: The promise, the reality, and the future of biotech. Harvard Business Press, Boston, MA, USA.

9. Levey AS, Atkins R, Coresh J, Cohen EP, Collins AJ, et al. (2007) Chronic kidney disease as a global public health problem: approaches and initiatives a position statement from Kidney Disease Improving Global Outcomes. Kidney Int 72: 247-259. 
Citation: Marin GH, Marin L, Haag G, Risso P, Errecalde J (2018) Erythropoietin Treatment in Chronic Renal Failure Anaemia-Biosimilar Option in the Rational Use of Medicine Process in Order to Reduced Public Health Economic Burden. J Bioanal Biomed 10:96-99. doi:10.4172/1948593X.1000214

10. Borget I, Grivel T (2010) Biosimilars and medico-economic factors. Bull Cancer 97: 589-595.

11. http://apps.who.int/medicinedocs/pdf/s4874s/s4874s.pdf

12. Farfan-Portet M-I, Gerkens S, Lepage-Nefkens I, Vinck I, Hulstaert F (2014) Are biosimilars the next tool to guarantee cost-containment for pharmaceutical expenditures? Eur J Health Econ 15: 223-228.

13. IMS Institute for Healthcare Informatics (2013) Declining medicine use and costs: for better or worse? A review of the use of medicines in the United States in 2012.

14. Aapro M, Cornes P, Sun D, Abraham IT (2012) Comparative cost efficiency across the European $\mathrm{G} 5$ countries of originators and a biosimilar erythropoiesis- stimulating agent to manage chemotherapy-induced anemia in patients with cancer. Ther Adv Med Oncol 4: 95-105.

15. Yu B (2016) Greater Potential Cost Savings With Biosimilar Use. Am J Manag Care 22: 378

16. Carlini R, Obrador G, Campistris N, Andrade L, Chifflet L, et al. (2014) The first report of the latin american society of nephrology and hypertension (SLANH) anemia committee in chronic hemodialysis patients. Nefrologia 34: 96-104.

17. Singh SC, Bagnato KM (2015) The economic implications of biosimilars. Am J Manag Care 21: s331-340.

18. https://www.bna.com/the-new-biosimilar-era-the-basics-the-landscape-andthe-future/?amp=true 